\title{
Dominasi Paradigma Pengelolaan Atur dan Awasi dalam SVLK: Evaluasi Laporan Implementasi Pengelolaan Dan Pemantauan Lingkungan Hidup pada Industri Furnitur di Jepara
}

\author{
Helmi Ferdian¹, Purwanto ${ }^{1,2}$, Haryo Santoso ${ }^{1,3}$ \\ ${ }^{1}$ Magister Ilmu Lingkungan , Sekolah Pascasarjana,Undip; email : helmi.alzafara@gmail.com \\ 2Departemen Teknik Kimia Universitas Diponegoro; email: purwanto@undip.ac.id \\ 3Fakultas Teknik Undip; email: haryokrmt@gmail.com
}

\begin{abstract}
ABSTRAK
Paradigma pengelolaan hidup Atur dan Awasi (ADA) merupakan sistem pengelolaan hidup yang banyak diberlakukan di negara-negara berkembang termasuk Indonesia. Implementasi sistem ADA tersebut sangat dominan dalam pelaksanaan SVLK. Sebagai salah satu pusat industri furnitur, Kabupaten Jepara menjadi daerah yang merasakan dampak langsung dari penerapan kebijakan SVLK. Penelitian ini bertujuan untuk mengevaluasi peranan SVLK dalam "menuntun" industri furniture di Jepara untuk melakukan pengelolaan lingkungan seperti dalam UKL UPL/DPLH yang telah dimilikinya. Penelitian dilakukan dengan metode survei melalui pendekatan analisis deskriptif. Sampel penelitian sebanyak 37 perusahaan yang diperoleh dengan menggunakan teknik convenience sampling atau sering juga disebut teknik Insidental. Tahapan penelitian meliputi wawancara dan penyebaran kuisioner serta review laporan pengelolaan dan pemantauan lingkungan untuk dikaji dan dievaluasi. Hasil penelitian diketahui bahwa paradigma ADA yang mengendalikan SVLK belum mampu berperan maksimal dalam mempengaruhi industri furnitur untuk mengeimplementasikan UKL UPL-nya
\end{abstract}

Kata kunci: $A D A, S V L K, U K L$ UPL, industri furnitur.

\begin{abstract}
Paradigm life management Organize and Supervise (ADA) is a management system that is a lot of life imposed on developing countries including Indonesia. Implementation of the ADA system is very dominant in the implementation of the SVLK. As a center for the furniture industry, Jepara district into areas that feel the direct impact of policy implementation SVLK. This study aimed to evaluate the role of SVLK in the "lead" in Jepara furniture industry for management of environment as the UKL UPL / DPLH he had. Research conducted by survey method through descriptive analysis approach. Samples are 37 companies that obtained by using a convenience sampling technique sometimes called Incidental techniques. Stages of research includes interviews and questionnaires and review management reports and environmental monitoring to be studied and evaluated. The survey results revealed that the controlling paradigm ADA SVLK has not been able to contribute the maximum in affecting the furniture industry for its mengeimplementasikan UKL-UPL
\end{abstract}

Keywords: $A D A, S V L K, U K L$ UPL, the furniture industry.

Cara sitasi: Ferdian, H., Purwanto, dan Santoso,H. (2016). Dominasi Paradigma Pengelolaan Atur dan Awasi dalam SLVK: Evaluasi Laporan Implementasi Pengelolaan dan Pemantauan Lingkungan Hidup pada Industri Furnitur di Jepara. Jurnal Ilmu Lingkungan,14(2),108-114, doi:10.14710/jil.14.2.108-114

\section{PENDAHULUAN}

Sistem Verifikasi Legalitas Kayu (SVLK) adalah sertifikasi hasil hutan produk pemerintah Indonesia. Mengacu pada Permenhut P.38/Menhut-II/2009, SVLK didefinisikan sebagai persyaratan untuk memenuhi legalitas kayu/produk yang dibuat berdasarkan kesepakatan para pihak (stakeholder) kehutanan yang memuat standard, kriteria, indikator, verifier, metode verifikasi, dan norma penilaian. Kemunculan SVLK dilatar belakangi oleh inisiatif pemerintah untuk mengatasi pembalakan liar dan mempromosikan kayu legal di Indonesia. Melalui verifikasi ini, diharapkan kayu yang ada di pasaran dapat dipertanggungjawabkan legalitasnya. Kedepannya tidak akan ada lagi aktivitas asal menebang pohon, asal menjual ataupun asal membeli kayu (Dharmawan dkk., 2012). Dengan demikian konsumen di luar negeri tidak perlu lagi meragukan legalitas kayu dari Indonesia sehingga para petani dan pelaku industri furnitur dapat meyakinkan pembeli 
Ferdian, H., Purwanto, dan Santoso,H. (2016). Dominasi Paradigma Pengelolaan Atur dan Awasi dalam SLVK: Evaluasi Laporan Implementasi Pengelolaan dan Pemantauan Lingkungan Hidup pada Industri Furnitur di Jepara. Jurnal IImu Lingkungan,14(2),108-114, doi:10.14710/jil.14.2.108-114

dari luar negeri akan keabsahan kayu yang digunakan. Imbasnya yaitu kenaikan nilai jual produk-produk mereka.

Awal diundangkannya SVLK melalui Permenhut No. P.38/Menhut II/2009 hanya menyasar pelaku perdagangan kayu di bagian hulu, sedangkan industri furnitur pemilik TDI ataupun IUI lanjutan dipersyaratkan kemudian melalui Permenhut P.68/Menhut-II/2011 yang merupakan perubahan pertama dari Permenhut No. P.38/Menhut II/2009. Sejak saat itu SVLK menjadi wajib bagi industri furnitur yang melakukan kegiatan ekspor. Perubahan kebijakan pemerintah tersebut turut merubah "kiblat" paradigma pengelolaan lingkungan dalam SVLK. Pemerintah menyiapkan aturan yang rinci terkait pelaksanaan SVLK termasuk menyusun juknis dan juklak pelaksanaannya. Tujuannya adalah untuk mengurangi pilihan pelaku usaha dalam usaha pemanfaatan lingkungan hidup. Ketidakpatuhan terhadap peraturan yang berlaku dapat diberikan sanksi denda ataupun tidak diperkenankan untuk memperoleh fasilitas pelayanan jasa dari pemerintah. Sistem pengelolaan hidup seperti ini dikenal dengan Atur dan Awasi (ADA) atau Command And Control (CAC).

Dalam sistem ADA, sikap dan kelakukan masyarakat terhadap lingkungan hidup diatur dengan perundang-undangan dan dibina melalui berbagai jenis instrumen suasif. Posisi pemerintah dalam sistem ADA tersebut sangat dominan. Komando pelaksanaan sebuah peraturan ini mengalir sangat kuat dari atas ke bawah sehingga bersifat sangat topdown dan instruktif serta birokratis. Masyarakat diharuskan melaksanakan sepeti apa yang tertulis dalam peraturan menurut interpretasi pejabat yang berwenang. Paradigma pengelolaan ADA ini sering gagal dalam menuntun industri agar berperilaku ramah lingkungan, terlebih jika pelaksanaan pengawasan dan implementasi penegakan hukumnya lemah (Sumarwoto, 2001)

Kabupaten Jepara merupakan salah satu daerah yang merasakan dampak langsung dari penerapan SVLK, karena Jepara merupakan salah satu daerah di Indonesia yang menjadi pusat berkembangnya industri furnitur. Kabupaten Jepara bahkan telah menjadi icon internasional sebagai daerah penghasil mebel tradisional jati dimana sekitar 71 negara di lima benua tercatat telah mengimpor produk Jepara (Haryatno, 2006). Sejak dimandatorykannya SVLK, salah satu dampak positif yang saat ini terpantau di Jepara yaitu jumlah industri furnitur yang menyusunan UKL UPL/DPLH meningkat secara signifkan. Berdasarkan data dari BLH Jepara diketahui bahwa sampai pada akhir 2015 tercatat ada 165 industri furnitur yang telah memiliki UKL UPL/DPLH. Fenomena ini diduga berhubungan erat dengan pelaksanan SVLK karena Dokumen lingkungan (Amdal/UKL UPL/SPPL) merupakan dokumen yang wajib dimiliki perusahaan untuk mengurus SVLK
Berdasarkan hal tersebut perlu dilakukan kajian terhadap efektivitas pengelolaan lingkungan terhadap industri furnitur di Jepara mengingat SVLK sangat kental dengan paradigma ADA. Penelitian ini dilakukan dengan menganalisis pelaksanaan laporan implementasi UKL UPL/DPLH medio semester I Tahun 2015 yang dilaporkan kepada BLH setiap 6 bulan sekali.

\section{METODE PENELITIAN}

Jenis penelitian ini adalah penelitian deskriptif dengan obyek penelitian yaitu industri furnitur yang telah menyusun UKL UPL dan melaporkan secara rutin implementasi pengelolaan dan pemantauan lingkungan hidup. Jumlah sampel sebanyak 37 perusahaan yang diperoleh menggunakan teknik convenience sampling atau teknik Insidental

Analisis data dilakukan berdasarkan dampakdampak yang wajib dikelola dan dipantau industri furnitur dalam UKL UPL nya. Dampak yang wajib dikelola tersebut dijadikan jenis penaatan yang wajib dipantau, Sedangkan kriteria dan sub kriteria disusun dengan memodifikasi dari kriteria proper. Kriteria dan sub kreteria tersebut terdiri dari:

1. Pengendalian pencemaran udara (ambien):, hasil pemantauan, baku mutu dan ketersediaan alat pengendal pencemaran udara

2. Pengendalian gangguan : hasil pemantauan dan baku mutu kebisingan

3. Pengelolaan Limbah B3: Izin TPS LB3, pendataan jenis dan volume limbah yang dihasilkan, pelaporan terhadap kegiatan pengelolaan yang dilakukan perusahaan

Sedangkan penilaian ketaatan dilakukan dengan memberikan skor (1-3) terhadap jenjang pada sub kreteria yang telah disusun, untuk skor 1 artinya tidak taat, skor 2 artinya belum taat, dan skor 3 artinya taat. Setelah itu skor untuk semua kriteria dijumlah dan didapat jumlah skor total (Andini, 2012). Tingkat ketaatan pemrakarsa berdasarkan skor total tersebut disajikan dalam Tabel 1.

Tabel 1. Tingkat Ketaatan

\begin{tabular}{lll}
\hline \multicolumn{2}{c}{ Skor Penilaian } & \\
\cline { 1 - 2 } $\begin{array}{l}\text { Menghasilkan } \\
\text { limbah B3 }\end{array}$ & $\begin{array}{l}\text { Tidak } \\
\text { menghasilkan } \\
\text { limbah B3 }\end{array}$ & $\begin{array}{l}\text { Ketaatan } \\
\end{array}$ \\
\hline $17-21$ & $10-12$ & Taat \\
$12-16$ & $7-9$ & Belum taat \\
$7-11$ & $4-6$ & Tidak taat \\
\hline
\end{tabular}

\section{HASIL DAN PEMBAHASAN}

\subsection{Dokumen Lingkungan sebagai syarat SVLK}

AMDAL ataupun UKL UPL merupakan jenis dokumen lingkungan hidup seperti yang disebutkan dalam Peratuan Pemerintah Nomor 27 Tahun 2012 tentang Izin Lingungan maupun Peraturan Menteri Lingkungan Hidup Nomor 16 Tahun 2012 tentang 
pedoman penyusunan dokumen lingkungan. Selain AMDAL dan UKL UPL, terdapat pula SPPL yang merupakan dokumen lingkungan untuk kegiatan/usaha yang berskala kecil

Dokumen lingkungan hidup tersebut wajib disusun oleh pemrakarsa kegiatan dan/atau usaha untuk dijadikan pedoman dalam pengelolaan dan pemantauan lingkungan yang dipersyaratkan dalam izin kegiatan dan/atau usaha oleh instansi yang bertanggung jawab. Dokumen lingkungan yang disusun oleh pemakarsa tersebut kemudian dinilai atau diperiksa oleh Instansi yang menangani lingkungan hidup. AMDAL yang telah dinilai dan dinyatakan layak lingkungan akan diterbitkan SK Kelayakan Lingkungan dan UKL UPL yang telah diperiksa dan direvisi sesuai arahan akan diberikan rekomendasi UKL UPL. SK Kelayakan Lingkungan dan Rekomendasi UKL UPL inilah yang kemudian menjadi dasar terbitnya izin lingkungan. Izin lingkungan tidak diberikan kepada kegiatan/usaha berskala kecil yang menyusun SPPL.

Perusahaan yang memegang izin lingkungan memiliki kewajiban membuat dan menyampaikan laporan pelaksanaan terhadap persyaratan dan kewajiban dalam Izin Lingkungan kepada Menteri, gubernur, atau bupati/walikota. Laporan yang dimaksud adalah laporan implementasi UKL UPL, yaitu laporan pemantauan terhadap upaya pengelolaan yang telah dilakukan oleh perusahaan sesuai dengan komitmennya didalam UKL UPL yang dimiliki perusahaan. Laporan tersebut wajib disampaikan secara berkala setiap 6 (enam) bulan kepada Kepala Badan Lingkungan hidup sebagai wakil dari Bupati (PP No. 27 Tahun 2012 pasal 53)

Kedudukan izin lingkungan, dokumen lingkungan dan juga laporan implementasinya dalam SVLK digunakan untuk memenuhi prinsip legalitas usaha. Berdasarkan juknis SVLK telah diatur secara rinci melalui Peraturan Direktur Jenderal Bina Usaha Kehutanan Nomor P.5/VI-BPPHH/2014 Jo Peraturan Direktur Jenderal Bina Usaha Kehutanan nomor NOMOR : P.1/VI-BPPHH/2015 tentang Standar dan Pedoman Pelaksanaan Penilaian Kinerja Pengelolaan Hutan Produksi Lestari dan Verifikasi Legalitas Kayu. Tahapan proses audit SVLK secara rinci dijelaskan pada lampiran 3 peraturan terebut yang meliputi permohonan verifikasi, perencanaan verifikasi, pelaksanaan verifikasi dan pelaporan. Sedangkan standar dan pedoman pelaksanaan verifikasi legalitas kayu yang digunakan sebagai pegangan oleh auditor LVLK mengacu pada lampiran 2. Standar verifikasi dalam lampiran 2 peraturan tersebut memuat prinsip, kriteria, indikator dan verifier sedangkan untuk pedomannya memuat metode dan norma penilaian.

Prinsip pertama dalam Standar verifikasi SVLK adalah prinsip legalitas yaitu mendukung terselenggaranya perdagangan kayu yang sah salah satu verifiernya adalah dokumen lingkungan (Amdal/DELH/UKL UPL/DPLH ataupun SPPL). Sedangkan norma penilaiannya adalah (1) tersedia dokumen lingkungan tersebut yang telah disahkan oleh instansi yang berwenang atau bukti pengurusan perpanjangan tersedia dari instansi yang berwenang dalam bentuk Surat Keterangan/Tanda Terima (2) tersedia laporan pengelolaan dan pemantauan lingkungan sesuai/merujuk pada rekomendasi perubahan RKL terakhir

\subsection{Kinerja Pengelolaan Lingkungan Hidup pada Industri Furnitur}

Berdasarkan data yang diperoleh dari Badan Lingkungan Hidup Kabupaten Jepara diketahui bahwa sejak diwajibkannya SVLK melalui Permenhut P.68/Menhut-II/2011 industri furnitur di Jepara yang menyusun UKL UPL meningkat secara drastis. Peningkatan tersebut mencapai $969 \%$ atau hampir 10 kali lipat. Jumlah Industri furnitur yang telah memiliki UKL UPL/DPLH sampai akhir pada 2014 dapat dilihat pada tabel 2.

Meskipun SVLK memiliki andil yang besar untuk "memaksa" industri furnitur agar menyusun UKL UPL/DPLH tetapi hal tersebut ternyata tidak menjamin terhadap upaya kelestarian lingkungan hidup. Berdasarkan hasil penelitian diketahui bahwa, dari total 139 industri furnitur yang telah memiliki izin lingkungan atau rekomendasi UKL UPL yang dipersamakan dengan izin lingkungan hanya 52 perusahaan yang melaporkan implementasi pengelolaan lingkungannya sampai pada semester I (Januari-Juni) Tahun 2015.

Tabel 2. Jumlah Industri furnitur yang telah memiliki UKL UPL/DPLH

\begin{tabular}{lll}
\hline & Penyusunan UKL UPL/DPLH & $\begin{array}{l}\text { Jumlah } \\
\text { (Perusahaan) }\end{array}$ \\
\hline 1 & Sebelum diwajibkannya SVLK (Sebelum 22 September 2011) & 13 \\
2 & Setelah diwajibkannya SVLK (September 2011 - 31 Desember 2014) & 126 \\
\hline \multicolumn{2}{l}{ Sumber : BLH Jepara 2015 }
\end{tabular}


Ferdian, H., Purwanto, dan Santoso,H. (2016). Dominasi Paradigma Pengelolaan Atur dan Awasi dalam SLVK: Evaluasi Laporan Implementasi Pengelolaan dan Pemantauan Lingkungan Hidup pada Industri Furnitur di Jepara. Jurnal Ilmu Lingkungan,14(2),108-114, doi:10.14710/jil.14.2.108-114

Tabel 3. Tingkat Penaatan Industri Furnitur

\begin{tabular}{|c|c|c|c|c|c|}
\hline \multirow{2}{*}{$\begin{array}{l}\text { No. } \\
\text { Sampel }\end{array}$} & \multicolumn{3}{|c|}{ Skor Per Jenis Penaatan } & \multirow[t]{2}{*}{ Skor Total } & \multirow{2}{*}{$\begin{array}{c}\text { Kategori } \\
\text { Tingkat Penaatan }\end{array}$} \\
\hline & $\begin{array}{l}\text { Pengendalian } \\
\text { Penc. Udara }\end{array}$ & $\begin{array}{l}\text { Pengendalian } \\
\text { Gangguan }\end{array}$ & $\begin{array}{l}\text { Pengelolaan } \\
\text { Limbah B3 }\end{array}$ & & \\
\hline 1 & 4 & 1 & 3 & 8 & Tidak Taat \\
\hline 2 & 4 & 1 & 3 & 8 & Tidak Taat \\
\hline 3 & 5 & 1 & 3 & 9 & Tidak Taat \\
\hline 4 & 5 & 1 & 3 & 9 & Tidak Taat \\
\hline 5 & 4 & 1 & 3 & 8 & Tidak Taat \\
\hline $6^{*}$ & 3 & 1 & - & 4 & Tidak Taat \\
\hline $7^{*}$ & 4 & 1 & - & 5 & Tidak Taat \\
\hline $8^{*}$ & 5 & 1 & - & 6 & Tidak Taat \\
\hline 9 & 5 & 1 & 3 & 9 & Tidak Taat \\
\hline 10 & 3 & 1 & 3 & 7 & Tidak Taat \\
\hline $11^{*}$ & 5 & 1 & - & 6 & Tidak Taat \\
\hline 12 & 5 & 1 & 3 & 9 & Tidak Taat \\
\hline 13 & 5 & 2 & 3 & 13 & Belum Taat \\
\hline $14^{*}$ & 3 & 1 & - & 4 & Tidak Taat \\
\hline 15 & 3 & 1 & 3 & 7 & Tidak Taat \\
\hline $16^{*}$ & 5 & 1 & - & 5 & Tidak Taat \\
\hline 17 & 4 & 1 & 3 & 8 & Tidak Taat \\
\hline 18 & 4 & 1 & 3 & 8 & Tidak Taat \\
\hline 19 & 4 & 1 & 3 & 8 & Tidak Taat \\
\hline 20 & 3 & 1 & 3 & 7 & Tidak Taat \\
\hline $21^{*}$ & 5 & 1 & - & 6 & Tidak Taat \\
\hline 22 & 5 & 1 & 4 & 10 & Tidak Taat \\
\hline 23 & 5 & 1 & 3 & 9 & Tidak Taat \\
\hline 24 & 3 & 1 & 3 & 7 & Tidak Taat \\
\hline 25 & 8 & 3 & 3 & 14 & Belum Taat \\
\hline 26 & 5 & 1 & 3 & 9 & Tidak Taat \\
\hline 27 & 5 & 1 & 3 & 9 & Tidak Taat \\
\hline 28 & 5 & 1 & 3 & 9 & Tidak Taat \\
\hline 29 & 5 & 1 & 3 & 9 & Tidak Taat \\
\hline 30 & 6 & 2 & 3 & 11 & Tidak Taat \\
\hline $31^{*}$ & 9 & 3 & - & 12 & Taat \\
\hline 32 & 8 & 2 & 3 & 13 & Belum Taat \\
\hline 33 & 9 & 3 & 3 & 15 & Belum Taat \\
\hline 34 & 7 & 2 & 3 & 12 & Belum Taat \\
\hline 35 & 7 & 2 & 3 & 12 & Belum Taat \\
\hline 36 & 8 & 3 & 3 & 14 & Belum Taat \\
\hline 37 & 8 & 2 & 4 & 14 & Belum Taat \\
\hline
\end{tabular}

Keterangan

* = Tidak menghasilkan limbah B3

Berdasarkan hasil Analisis dan Skoring Kinerja Pengelolaan Lingkungan Industri Furnitur di Jepara tersebut sebanyak 75,68 \% perusahaan tidak taat dalam melakakukan pengelolaan lingkungan, 21,62 \% belum taat dan hanya 2,7 $\%$ perusahaan yang sudah taat. Hasil Rekapitulasi Tingkat Penaatan Industri Furnitur di Jepara selengkapnya dapat pada Tabel 4 . 
Tabel 4. Hasil Rekapitulasi Tingkat Penaatan Industri Furnitur di Jepara

\begin{tabular}{lllll}
\hline \multirow{2}{*}{ Kategori } & \multicolumn{2}{c}{ Skor Penilaian } & $\begin{array}{l}\text { Jumlah } \\
\text { perusahaan }\end{array}$ & Prosentase (\%) \\
\cline { 2 - 5 } Ketaatan & Menghasilk & Tidak & & \\
& an limbah & menghasilkan & & \\
& B3 & limbah B3 & & 2,70 \\
& $17-21$ & $10-12$ & 1 & 21,62 \\
Taat & $7-9$ & 8 & 75,68 \\
Belum taat & $12-16$ & $4-6$ & 28 & $\mathbf{1 0 0 \%}$ \\
Tidak taat & $7-11$ & & $\mathbf{3 7}$ & \\
\hline Total & & &
\end{tabular}

Rendahnya tingkat ketaatan industri furnitur disebabkan karena perusahaan tidak melakukan kewajiban untuk memantau komponen lingkungan yang terkena dampak (kualitas udara ambien dan kebisingan) seperti yang tercantum dalam UKL UPL.DPLH yan telah dimiliki perusahaan. Berdasarkan hasil evaluasi terhadap 37 sampel perusahaan yang telah melaporkan implementasi pengelolaan lingkungannya, diketahui sebanyak 10 perusahaan atau 27 \%-nya yang benar-benar melakukan pengelolaan dan pemantauan. Sedangkan sisanya sebanyak $73 \%$ industri furnitur tidak melakukan pemantauan kualitas udara ambien dan kebisingan seperti komitmen perusahaan didalam UKL UPL/DPLH yang telah disusunnya. Sehingga yang terjadi adalah laporan implementasi yang disusun dan laporkan ke BLH Jepara hanya sekedar formalitas untuk memperoleh pengesahan saja atau bukti tanda terima telah mengirim laporan. Prosentase industri furnitur yang melaksanaan pemantauan udara ambien dan kebisingan tersaji dalam gambar 1 .

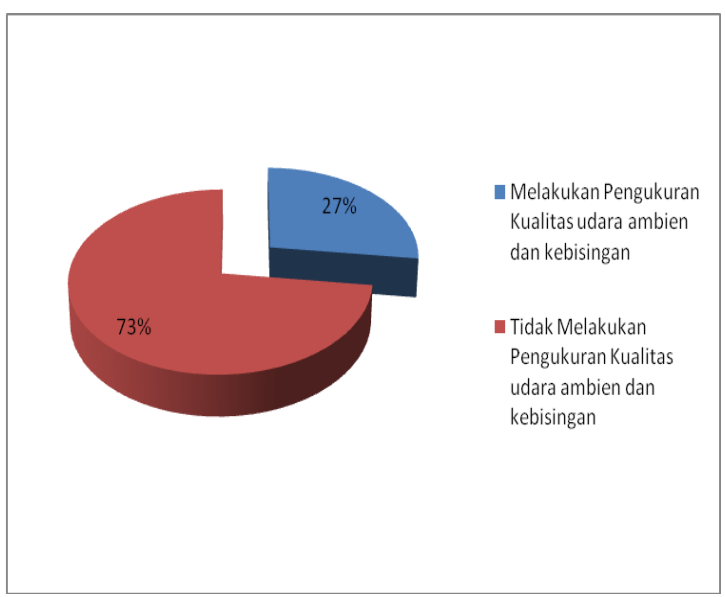

Gambar 1. Prosentase industri furnitur yang melaksanaan pemantauan udara ambien dan kebisingan

Dalam hal pelaksanaan pengelolaan limbah B3 yang wajib dilakukan oleh industri yang menghasilkan limbah B3, diketahui bahwa industri furnitur di Jepara belum ada yang memiliki izin Tempat Penyinpanan Sementara Limbah B3 (TPS LB3). Hal ini sangat mempengaruhi penilaian ketaatan perusahaan. Berdasarkan hasil wawancara dan penelusuran langsung di lapangan diketahui bahwa industri furnitur yang ada di Jepara selama ini belum mengetahui tentang aturan-aturan terkait limbah B3.
Jenis-jenis limbah B3 maupun cara-cara melakukan pengelolaan limbah B3 sama sekali belum diketahui oleh pelaku industri furnitur. Pemahaman industri furnitur terhadap limbah B3 yang diketahui selama ini yaitu menganggap barang/limbah tersebut sebagai limbah biasa yang dapat dikelola seperti sampahsampah pada umumnya. Hasil penelusuran dilapangan didapatkan bahwa bekas kemasan kaleng bahan finishing banyak dibiarkan dan ditumpuk di pojok-pojok ruangan tertentu, sedangkan pada beberapa perusahaan yang memiliki manajemen lebih bagus mereka menempatkan kaleng bekas finshing tersebut dalam ruang tertentu (gudang) yang tertutup. Untuk selanjutnya di jual kepada pengepul (pihak ke-3) atau sebagian dimanfaatkan kembali oleh karyawan. Pihak ke-3 dalam hal ini adalah pengepul sampah biasa bukan sebuah perusahaan dengan spesifikasi khusus yang telah memiliki izin pengumpulan, pemanfaatan, ataupun pengolahan limbah B3.

\subsection{Kegagalan Paradigma Pengelolaan ADA dalam Mengupayakan Tata Kelola Lingkungan Industri Mebel}

Pengelolaan lingkungan merupakan upaya pengelolaan sumber daya alam. Dalam bukunya yang berjudul Atur Diri Sendiri : Paradigma Baru Pengelolaan Lingkungan Hidup (2001) Otto Sumarwoto mendefinisikan pengelolan lingkungan sebagai usaha sadar dan berencana untuk mengurangi dampak kegiatan terhadap lingkungan hidup sampai pada tingkat yang minimum dan untuk mendapatkan manfaat yang optimum dari lingkungan hidup untuk mencapai kesejahteraan yang berkelanjutan. Tujuan pengelolaan lingkungan hidup ini adalah terlaksananya pembangunan berwawasan lingkungan dan terkendalinya pemanfaatan sumber daya alam secara bijaksana.

SVLK merupakan salah satu produk yang diciptakan oleh pemerintah untuk menjamin pengelolan lingkungan hidup. SVLK dirancang pemerintah untuk menjamin kelestarian pengelolaan hutan dan atau legalitas kayu serta ketelusuran kayu melalui sertifikasi pengelolaan hutan (SPHL) dan sertifikasi legalitas kayu (SLK). Sehingga secara "spesifik" SVLK hadir sebagai intstrumen perbaikan tata kelola kehutanan. Dalam perkembangannya, pelaksanaanya SVLK ini kemudian didukung oleh kementerian perindustrian, kementerian perdagangan bahkan juga lembaga-lembaga lain 
Ferdian, H., Purwanto, dan Santoso,H. (2016). Dominasi Paradigma Pengelolaan Atur dan Awasi dalam SLVK: Evaluasi Laporan Implementasi Pengelolaan dan Pemantauan Lingkungan Hidup pada Industri Furnitur di Jepara. Jurnal Ilmu Lingkungan,14(2),108-114, doi:10.14710/jil.14.2.108-114

seperti Ditjen Bea dan Cukai ataupun KAN. Dukungan tersebut berupa penerapan SVLK diberbagai bidang dan menjadi sebuah syarat yang harus dipenuhi oleh industri yang ingin mendapatkan layanan dan fasilitas dari pemerintah.

Pada pelaksanaan, pemerintah menyiapkan juknis dan juklak yang rinci, sehingga SVLK menjadi sangat kental dengan paradigma pengelolaan lingkungan Atur dan Awasi (ADA). Dalam sistem ADA sikap dan kelakukan terhadap lingkungan hidup diatur dengan perundang-undangan dan dibina melalui berbagai jenis instrumen suasif. Konsekuensi dari sistem ADA ini akan bertentangan dengan sifat egoisme dan naluri manusia (Sumarwoto, 2001). Adanya sifat egoisme yang mengakar pada manusia ini cenderung untuk menghindari tindakan yang merugikan dirinya, termasuk paksaan terhadap aturan yang telah disusun pemerintah. Karena memenuhi kewajibannya dalam melakukan pengelolaan lingkungan berarti akan ada konsekuensi biaya yang harus dikeluarkan perusahaan untuk kegiatan tersebut, sehingga sedapat mungkin untuk dihindari. Menurut soemarwoto (2002) keuntungan yang didapatkan perusahaan dengan melanggar peraturan jauh lebih tinggi dibandingkan dengan resiko biaya yang harus dikeluarkan perusahaan karena penindakan pelanggaran.

Berdasarkan hasil penelitian terhadap kinerja pengelolaan dan pemantauan lingkungan industri furnitur diketahui bahwa dominasi ADA dalam pelaksanaan SVLK tidak berhasil mendorong perusahaan untuk berlaku ramah terhadap lingkungan. SVLK memang telah berhasil menangkis isu illegal loging terhadap produk hutan Indonesia dan mengembalikan kepercayaan masyarakat dunia terhadap produk hasil hutan indonesia tetapi belum berhasil dalam menciptakan tata kelola lingkungan hidup yang substantif di lingkungan perusahaan. Industri furnitur banyak yang lalai dalam melakukan pemantauan lingkungan hidup, paremater pencemaran sering melebihi baku mutu lingkungan dan pengelolaan limbah B3 yang belum dilaksanakan sesuai peraturan. Hasil penelitian menunjukan bahwa UKL UPL/DPLH yang disusun perusahaan hanya digunakan sebagai syarat untuk memenuhi perijinan atau proses verifikasi SVLK dan belum menjadi acuan dalam melakukan pengelolaan di lingkungan industrinya. Motivasi perusahan dalam hal ini adalah untuk menghilangkan "hambatan" eksport, yang artinya industri furnitur melakukan pemenuhan syarat SVLK, termasuk menyusun UKL UPL/ DPLH, dominan karena paksaan pemerintah bukan berasal dari kesadarannya sendiri. Pelaku industri furnitur di Jepara mengetahui dengan benar bahwa melakukan pengelolaan lingkungan membutuhkan biaya yang tidak sedikit. Hal ini akan mengurangi keuntungan perusahaan sehingga sedapat mungkin mereka dihindari. Industri furnitur di Jepara juga bukan perusahaan go publik sehingga tidak memerlukan image "go green" dari konsumen dan tidak ada tekanan bagi mereka ketika tidak ramah terhadap lingkungan.

Membandingkan dengan penelitian Santoso dkk. (2014) terhadap sertifikasi kayu CoC yang menggunakan pendekatan paradigma Atur Diri Sendiri (ADS) diketahui bahwa dalam ecolabeling yang bersifat voluntary ecolabel, industri furnitur "ditununtun" untuk ramah lingkungan dan mendorong produsen sadar lingkungan meskipun pada awalnya sertifikasi tersebut disebabkan oleh tekanan bisnis (ekonomi), bukan langsung dari kesadaran produsen. Hal yang sama juga terjadi pada ISO 14001 yang sangat "kental" dengan paradigma Atur Diri Sendiri (ADS).

\section{KESIMPULAN}

Berdasarkan hasil evaluasi terhadap laporan implementasi UKL UPL/DPLH Industri furntur di Jepara maka dapat ditarik kesimpulan sebagai berikut

1. SVLK yang sangat dominan dengan paradigma pengelolaan hidup Atur dan Awasi (ADA) belum berhasil mendorong perusahaan untuk berlaku ramah terhadap lingkungan.

2. UKL UPL/DPLH disusun perusahaan hanya digunakan sebagai syarat untuk memenuhi perijinan atau proses verifikasi SVLK dan belum menjadi acuan dalam melakukan tata kelola lingkungan di lingkungan industrinya.

\section{SARAN}

Saran untuk pemerintah terhadap keberlanjutan pelaksaanaan SVLK yaitu :

1. Pemerintah Pusat perlu memperbaiki prosedur SVLK dengan mengedepankan pendekatan paradigma pengelolaan hidup Atur Diri Sendiri (ADS) dan menciptakan rangsangan-rangsangan yang bersifat ekonomi.

2. Mewajibkan industri furnitur yang menginginkan sertifikat SVLK agar terlebih dahulu memiliki peringkat biru dalam Proper, memiliki sertifikat ISO ataupun sejenisnya untuk menjamin tata kelola lingkungan industrinya.

\section{DAFTAR PUSTAKA}

Dharmawan AH, Nugroho B, Kartodihardjo H, Kolopaking LM, Boer R ,2012. SVLK, Jalan Menuju REDD+. Forest Governance and Multistakeholder Forestry Programme, Jakarta

Goesty PA, Samekto Adji, Sasongko DP ,2012. Analisis Penaatan Pemrakarsa Kegiatan Bidang Kesehatan Di Kota Magelang Terhadap Pengelolaan Dan Pemantauan Lingkungan Hidup. Jurnal Ilmu Lingkungan Volume 10 Issue 2 (89-94). Undip, Semarang

Peraturan Direktur Jenderal Bina Usaha Kehutanan Nomor P.5/VIBPPHH/2014 tentang Standar dan Pedoman Pelaksanaan Penilaian Kinerja Pengelolaan Hutan Produksi Lestari dan Verifikasi Legalitas Kayu

Peraturan Menteri Kehutanan Republik Indonesia Nomor : P.43/Menhut-II/2014 Tentang Standar Dan Pedoman Penilaian Kinerja Pengelolaan Hutan Produksi Lestari Dan 
Verifikasi Legalitas Kayu Pada Pemegang Izin Atau Pada Hutan Hak

Peraturan Menteri Negara Lingkungan Hidup Nomor 31 tahun 2009 tentang Pembinaan dan Pengawasan Penerapan Sistem Manajemen Lingkungan, Ekolabel, Produksi Bersih, dan Teknologi Berwawasan Lingkungan di Daerah.

Peraturan Menteri Negara Lingkungan Hidup Nomor 16 Tahun 2012 tentang Pedoman Penyusunan Dokumen Lingkungan

Peraturan Menteri Negara Lingkungan Hidup No. 6 Tahun 2013 tentang Program Penilaian Peringkat Kinerja Perusahaan Dalam Pengelolaan Lingkungan Hidup.

Peraturan Pemerintah nomor 27 Tahun 2012 Tentang Izin Lingkungan

Peraturan Menteri Kehutanan Republik Indonesia Nomor P.38/Menhut II/2009 tentang Standar Dan Pedoman Penilaian Kinerja Pengelolaan Hutan Produksi Lestari Dan Verifikasi Legalitas Kayu Pada Pemegang Izin Atau Pada Hutan Hak

Peraturan Menteri Kehutanan Republik Indonesia Nomor P.68/Menhut-II/2011tentang perubahan pertama atas permenhut No. P.38/Menhut II/2009 tentang Standar Dan Pedoman Penilaian Kinerja Pengelolaan Hutan Produksi Lestari Dan Verifikasi Legalitas Kayu Pada Pemegang Izin Atau Pada Hutan Hak

Santoso H, Arvianto A, Fanani Z. 2014. Dampak Sertifikasi Ekolabel Terhadap Sustainabilitas Industri Furnitur. Prosiding SNST ke-5 Tahun 2014. Fakultas Teknis Universitas Wahud Hasyis, Semarang

Sumarwoto, Otto, 2001. Atur Diri Sendiri : Paradigma Baru Pengelolaan Lingkungan Hidup. Gajah Mada University Press, Yogjakarta 